\title{
The bees are back in town
}

Pollinators in an urban ecosystem

The growing urbanisation of the landscape poses a major could have a severe impact on agricultural production as many of the crops that we rely on could not produce seeds without pollination. Working with the Project, Professors Cindy Bennington and Peter May investigate poll hator visitation Stetson University in Florida compare pollinators in an urban ecosystem to those in a larger conservation area. threat to insect pollinators. The insects, especially bee species, Volusia Sandhill Pollinator

ollinators are any animals (usually insects) that transfer pollen without them around $75 \%$ of flowering plants would be unable to reproduce for food and other products The grow of towns and cities ('urbanisation') means the reduction in natural environments where these pollinator species thrive.

While declines in European honeybee populations have drawn global attention because of their importance to crop pollination, declines in native species worldwide are causing concern for both agriculture and native plant reproduction.

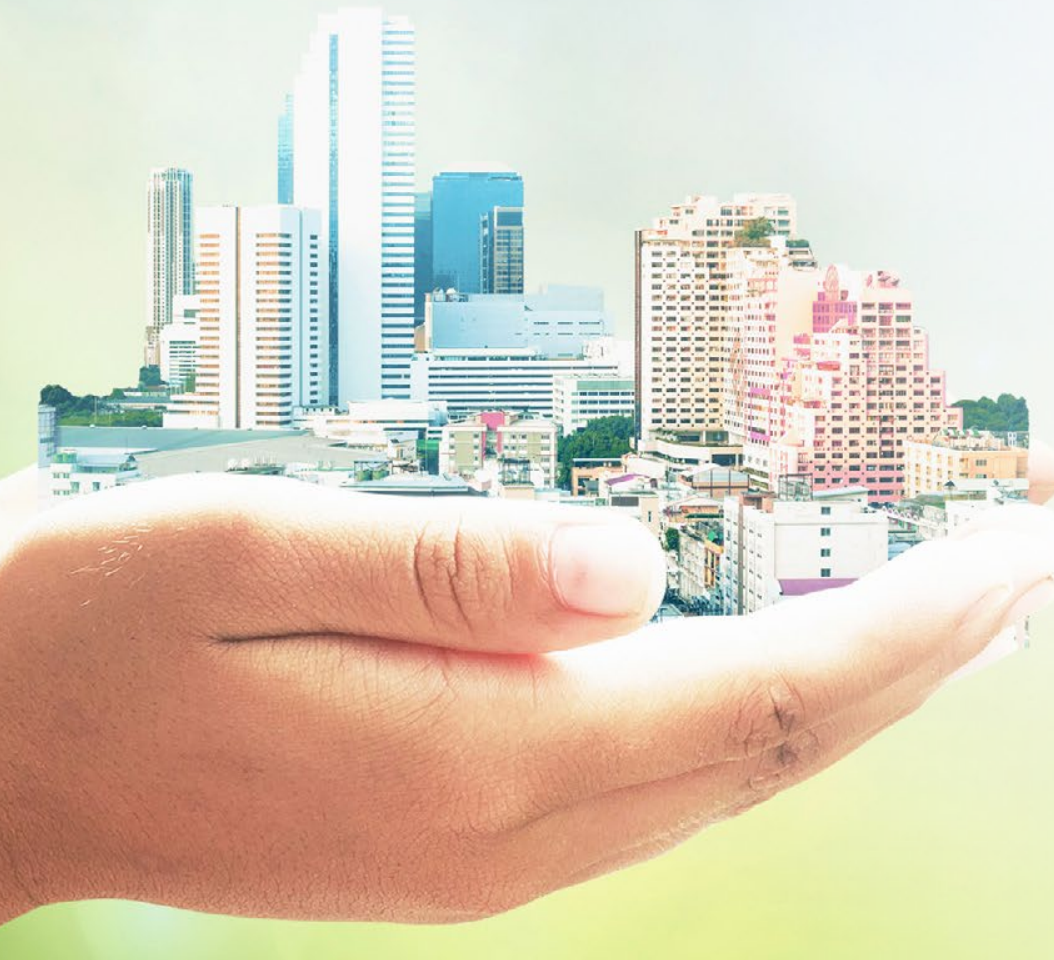

Stetson University researchers Professor Cindy Bennington and Professor Peter May investigate the pollinators visiting ecosystem to compare in an urban ecosystem to compare how the numbers to thos found in a larger consempation area. The question is, does this small area provide enough habitat and food to support a diverse and abundant insect pollinator community?

\section{THE VOLUSIA SANDHILL}

ECOSYSTEM

In 2011 a small field located near the Gillespie Museum on the Stetson

University campus in Florida was selected to be restored to the natural sandhill ecosystem that would have dominated the area prior to urbanisation (European settlement). These sandhills are so called because of the deep, sandy soil of the area, but the dominant features of the landscape were the large, widely spaced involved planting more than 80 native tree species, mostly longleaf pine, and the development of an understory of plants and grasses. This small fragment of restored ecosystem is still immature. The trees are young and don't provide the same high, thick canopy as you would find in a more mature ecosystem, which affects the smaller plants growing below. Yet already you can see the difference from the neglected lawn that was there previously, especially as pollinators return to visit the many flowering plants.

This area, known as the Volusia Sandhill Ecosystem, is now a teaching area to educate visitors about the natural plants and insects. Anyone is welcome

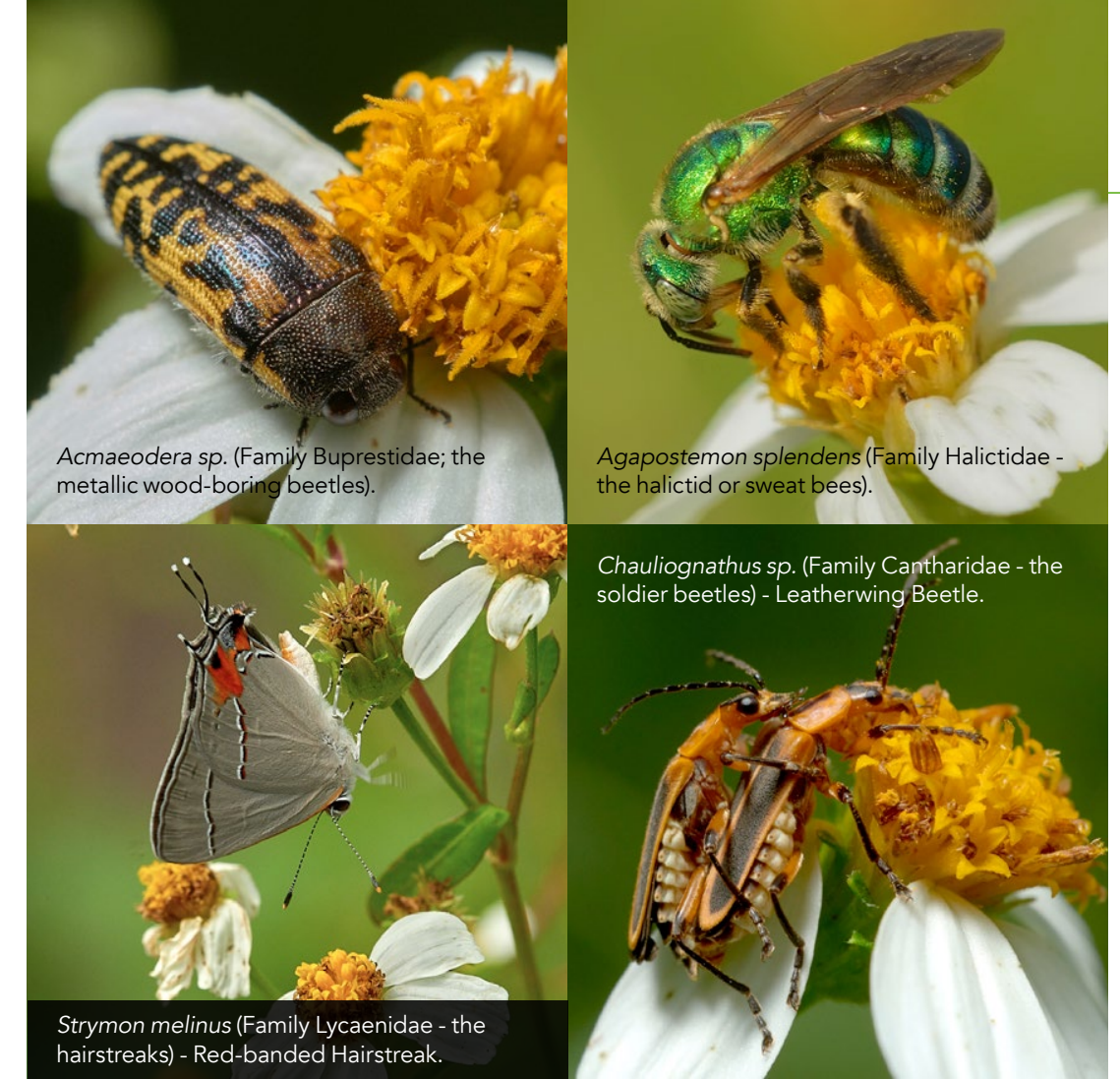

...the Volusia Sandhill Ecosystem is now a teaching area to educate visitors about the natural landscape of the area and the native plants and insects.

to visit the Gillespie Museum and take part in the Volusia Sandhill Pollinator Project - where volunteers can record pollinator activity and contribute to the ongoing data collection.

Professors Bennington and May are interested in how well this small area of restored sandhill ecosystem might support pollinators, in comparison to a is surrounded by an urban ecosystem of residential, business and university campus areas. The ability of this and any small, isolated fragment of semi-natural habitat to support insect life depends upon its ability to provide suitable habitat for a diversity of species of plants and insects.

The contrast to this fragment is the Heart sland Conservation Area (DeLeon Springs, Florida), north of the Volusia Sandhill and Stetson University campus, which is more than 5700 hectares of semi-natural habitat. This covers a variety of ecosystems including sandhills, and the plant understory of the sandhills is made up of many native flowering plants means thany native pollinators. This
Volusia Sandhill can be compared to the pollinators visiting the sandhills of Heart if the sane number and species of pollinators are present in the urban ecosystem as in the larger notural area.

PLANT-POLLINATOR INTERACTIONS

The pollinators we are most familiar with

are bees, though other insects including wasps, butterflies, beetles, and flies are also common pollinators. Insects visit the flowers to access the nectar and pollen as a food source, and in the process carry pollen between plants. Some plants, referred to as 'specialists', are only pollinated by one group of insects (for example, hey may only attract flies, or have the pollen situated such that only bees can collect it), and others may be 'generalists', meaning that any insect that pollen. To compare pollinators, two pollen. To compare pollinators, two plan the Volusia Sandhill Ecosystem and the Heart Island Conservation Area - one generalist and one specialist.

The two areas differ in the plant species present, due to a variety of factors including the maturity of e ecosystem and the soi quality, but Bidens alba (B. alba; a generalist)
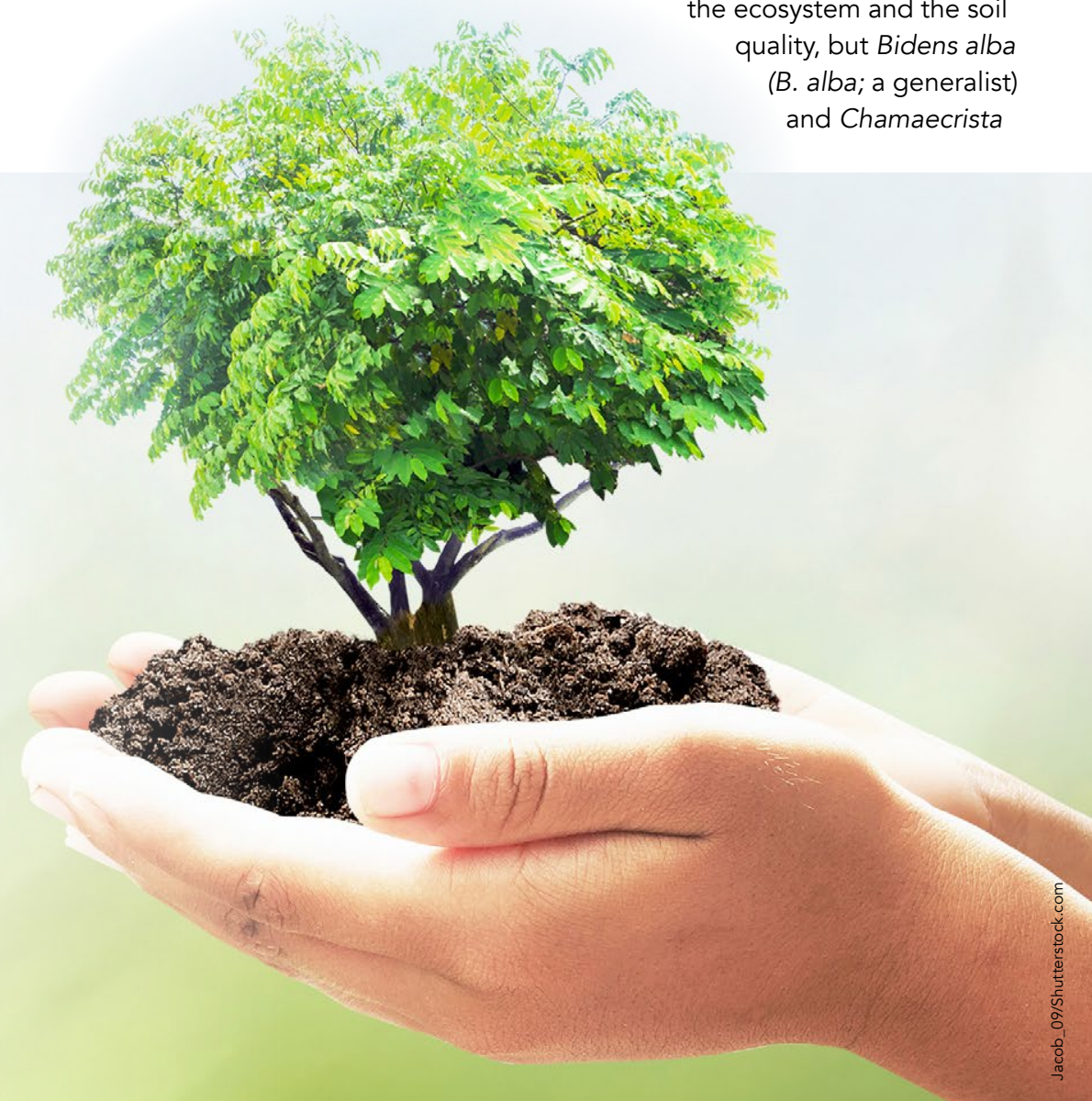
fasciculata (C. fasciculata; a specialist) were present in both ecosystems and c. fasciculata is 'buzz-pollinated', which means that the vibrations from he buzzing of a bee vale required to release the pollen from the flower. It is expected that specialist plant species would suffer from the reduced number of available pollinators in an urban cosystem more than a generalist plant species, and so it is of interest to compare the pollination visitation to both specialists and generalists in urban and conservation areas.

\section{WELCOME VISITORS}

The researchers counted insect visitors to B. alba and C. fasciculata flowers both sites between May and August fout three years (2016 - 2018) and flind a surprising result. there were both plants at the Volusia Sandhill Ecosystem than at the Heart Island Conservation Area. Although there was no statistical difference in the number of insects visiting the plants in each area, the total numbers were higher for the Volusia Sandhill and this is not what was expected in the urban ecosystem.

Most of the visitors to both plant at both sites were native bees, but there was a much greater diversity of visitors to $B$. alba at the Heart Islan Conservation Area. Over $70 \%$ of pollinator visitation to B. alba at the Volusia Sandhill were Hymenoptera (bees and wasps), but at the Hear f visitors Lepidopter only $41 \%$ butterflies) made up 31\% of visitors theart Island, and Diptera (flies) Coleoptera (beetles) together made up another $14 \%$. This means there is a much greater diversity of insects present at Heart Island than at the Volusia Sandhill, where Lepidoptera, Diptera and Coleoptera all together only made up a little over $12 \%$ of the visitors to $B$. alba.

As expected, the most common pollinator to visit $C$. fasciculata was the bumblebee (Bombus spp.), and while there were slightly more visitors at the Volusia Sandhil, bumblebees were the large majortity at both sites indicating no significant difference in the

\section{URBAN POLUNATORS}

This research suggests that this smal and immature fragment of restored community of bees in an urbar ecosystem. Potentially this could also be assisted by the non-native plants in the gardens and green areas in the residential, business and university campus surroundings, and perhaps some cavity-nesting species can find suitable habitats on the sides of buildings. The study supports previous research which found that Hymenoptera are more resilient to urbanisation than other pollinator species. The species composition at each site varied a great deal, however, and so it seems that specific bee and wasp species are differently impacted by the changing ecosystem. The surface area available to ground-nesting species supplies are likely to also play a role in determining which species thrive in an urban environment.

This research suggests that this small and immature fragment of restored habitat could be enough to support a community of bees in an urban ecosystem.

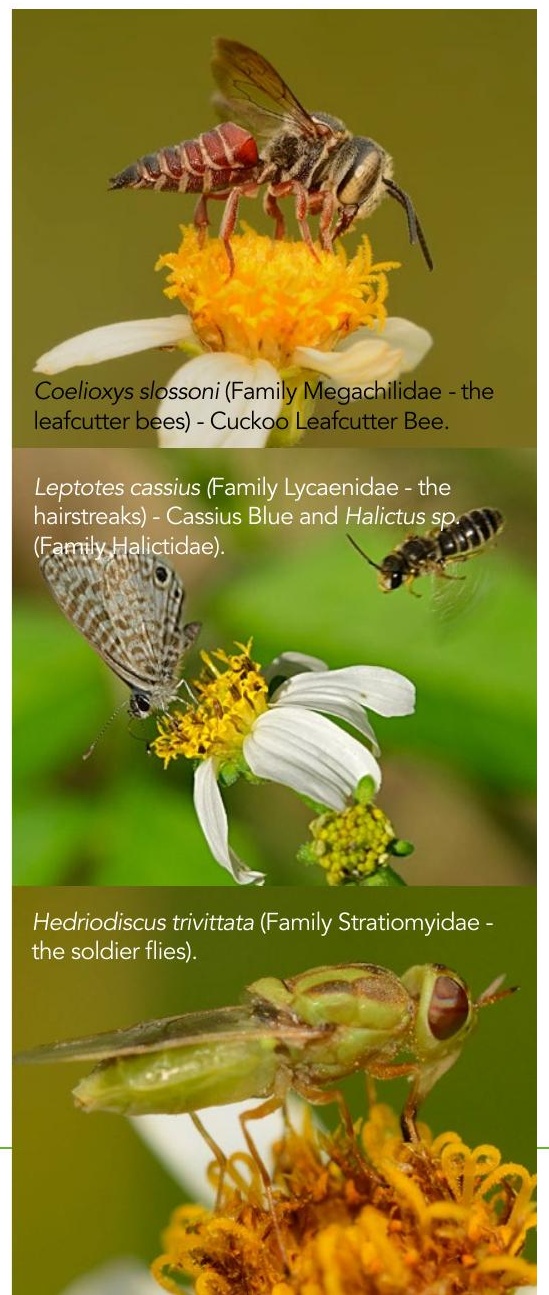

作 the pollinatorned as being due to perato (a) spp. can visit many plants including both specialists and generalists. The low numbers of beetle and butterfly visitors to the plants at the Volusia Sandhill Ecosystem suggests these are more sensitive to urbanisation, and this is again likely due to these insects having requirements (other than food in the form of nectar) that are not met in an

Professors Bennington and May (and volunteers with the Volusia Sandhill Pollinator Project) continue to record pollinator visitation to the Volusia Sandhi cosystem each summer, and hope to by increating the avaity of pollinators by increasing the available larval food provide resources to insects year

\section{Behind the Research}

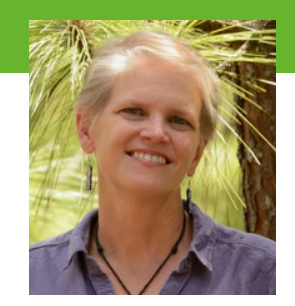

Cindy

Bennington

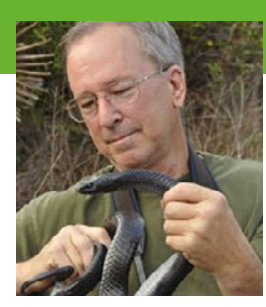

Peter

May

E: cbenning@stetson.edu E: pmay@stetson.edu T: $+1(386)$ 822-8170 W: https://www.stetson.edu/other/faculty/cynthia bennington.php W: hteps.hwhw.

Research Objectives

Professors Cindy Bennington and Peter May assess the ability of the Volusia Sandhill Ecoystem to support wild insect pollinators.

\section{Detail}

\section{Address}

421 N. Woodland Blvd.

DeLand, Florida 327 the pollinators in the Volusia Sandhill, a
campus restoration site, was a natural pairing given their contributions to the site's development and their respective expertise in plants and insects.

Cindy and Peter are both Professors of Biology at Stetson University, a small liberal arts college in Florida. Studying for decades, they got married in the

\section{Funding}

Stetson Univers
Program

\section{References}

Bennington, C. and May, P. (2020). Pollinator
Communities of Restored Sandhills: a Comparison

of Insect Visitation Rates to Generalist and Specialist

Flowering Plants in Sandhill Ecosystems of Central Florida. Natural Areas Journal, 40(2), 168-178. https://doi. org/10.3375/043.040.0208

The Volusia Sandhill Ecosystem. [online]. Stetson University webpage. Available at. https.//Www.stetson.edu/other/ gillespie-museum/vse/index.php [Accessed 18 Sept. 2020].

Volusia Sandhill Pollinator Project. [online]. Stetson Univershy webpage. Avallable at. hips.//Ww.stetson. [Accessed 23 Sept 2020]

\section{Personal Response}

\section{What could this mean in terms of protecting} native pollinator species
and climate change?

II Our research is consistent with that of others who have found that small urban ecosytems can provide habitat for plants and invertebrates in an increasingly humandominated landscape, though the pollinator communities in urban fragments may be a novel mix of species. The withstand accelerating climate change requires continued
investigation.

STETSON UNIVERSITY

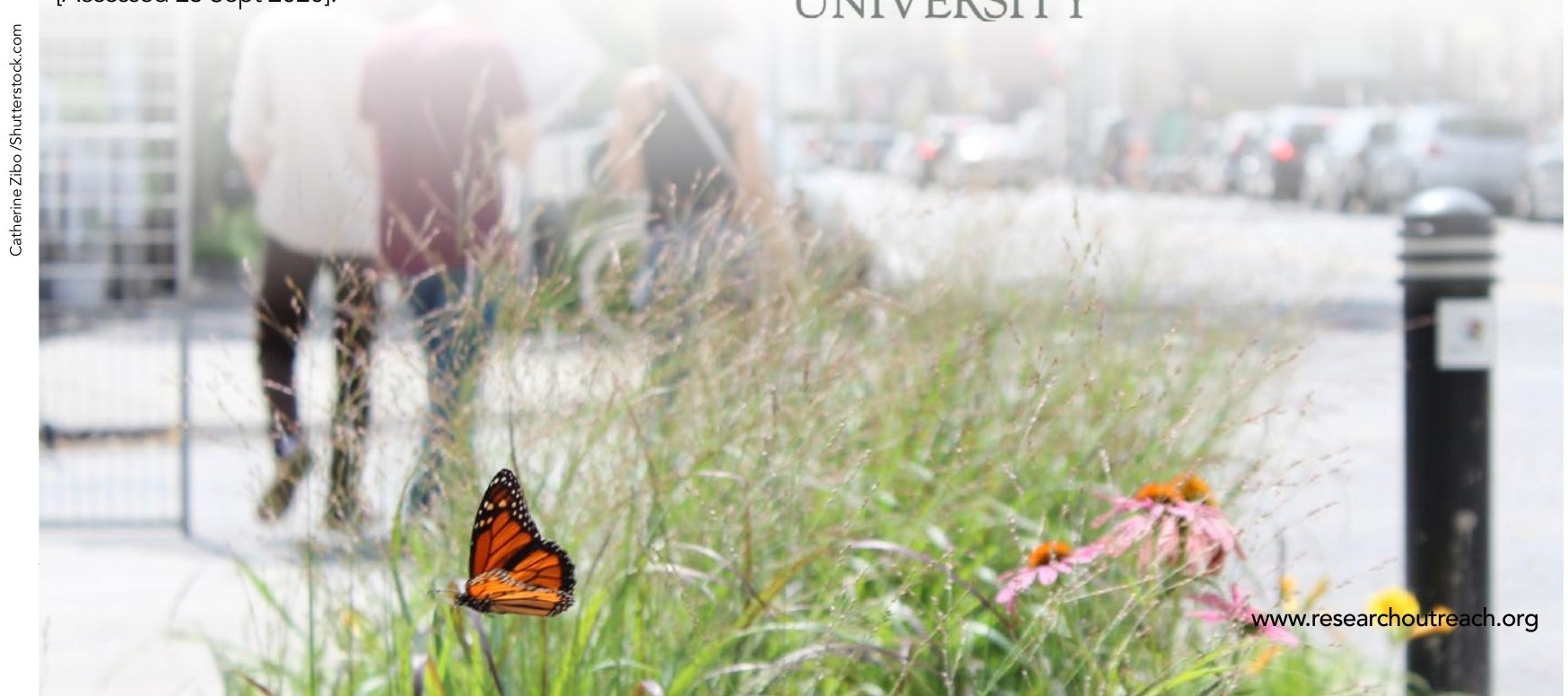

